\title{
YAP1 enhances cell proliferation, migration, and invasion of gastric cancer in vitro and in vivo
}

\author{
Dan Sun ${ }^{1}$, Xiaoting $\mathrm{Li}^{2}$, Yingjian $\mathrm{He}^{2}$, Wenhui $\mathrm{Li}^{1}$, Ying Wang ${ }^{1}$, Huan Wang ${ }^{1}$, \\ Shanshan Jiang ${ }^{1}$, Yan Xin ${ }^{1}$ \\ ${ }^{1}$ Laboratory of Gastrointestinal Onco-Pathology, Cancer Institute and General Surgery Institute, The First Affiliated Hospital \\ of China Medical University, Shenyang 110001, Liaoning Province, China \\ ${ }^{2}$ Key laboratory of Carcinogenesis and Translational Research (Ministry of Education), Peking University Cancer Hospital and \\ Institute, Beijing, 100142, China
}

Correspondence to: Yan Xin, email: yxin@mail.cmu.edu.cn

Keywords: yes-associated protein1/YAP1, gastric cancer, proliferation, migration, invasion

Received: March 15, $2016 \quad$ Accepted: October 31, $2016 \quad$ Published: November 07, 2016

\section{ABSTRACT}

Yes-associated protein 1 (YAP1) plays an important role in the development of carcinomas such as breast, colorectal, and gastric (GC) cancers, but the role of YAP1 in GC has not been investigated comprehensively. The present study strongly suggests that YAP1 and P62 were significantly up-regulated in GC specimens, compared with normal gastric mucosa. In addition, the YAP1 ${ }^{\text {high }} \mathbf{P 6 2}^{\text {high }}$ expression was independently associated with poor prognosis in GC (hazard ratio: 1.334, 95\% confidence interval: 1.045-1.704, $P=0.021$ ). Stable YAP1 silencing inhibited the proliferation, migration, and invasion of BGC-823 GC cells in vitro and inhibited the growth of xenograft tumor and hematogenous metastasis of BGC-823 GC cells in vivo. The mechanism was associated with inhibited extracellular signal-regulated kinases (ERK)1/2 phosphorylation, elevated E-cadherin protein expression and decreased vimentin protein expression, down-regulated $\beta$-catenin protein expression and elevated a-catenin protein expression, and down-regulated long non-coding RNA (IncRNA) expressions including HOX transcript antisense RNA (HOTAIR), H19, metastasis-associated lung adenocarcinoma transcript 1 (MALAT1), human large tumor suppressor-2 (LATS2)-AS1-001, and LATS2. YAP1 over-expression promoted the proliferation, migration, and invasion of human immortalized normal gastric mucosa GES-1 cells in vitro by reversing the above signal molecules. Subcutaneous inoculation of GES-1 cells and YAP1-over-expressing GES-1 cells into nude mice did not generate tumors. We successfully established the xenograft tumor models using MKN-45 GC cells, but immunochemistry showed that there was no YAP1 expression in MKN-45 cells. These results suggest that YAP1 is not a direct factor affecting tumor formation, but could accelerate tumor growth and metastasis. Collectively, this study highlights an important role for YAP1 as a promoter of GC growth and metastasis, and suggests that YAP1 could possibly be a potential treatment target for GC.

\section{INTRODUCTION}

Gastric cancer is a leading cause of cancer-related death in China and most gastric cancer patients are already diagnosed with late stage disease [1]. Despite the best available therapeutic approaches, the 5-year survival of patients with GC ranges from $95 \%$ for stage IA to $10 \%$ for stage IIIC and 3\% for stage IV [2]. Therefore, there is a need for the identification of novel targets for therapies.
The Hippo-YAP signaling pathway regulates cell proliferation and apoptosis [3]. Within this pathway, the Yes-associated protein 1 (YAP1) is a negative regulator of the Hippo-YAP pathway [4]. The WW domain of YAP1 directly interacts with the transcription factor polyomavirus enhancer binding protein $2 \alpha$ (PEBP2 $\alpha$ ) through the PPXY motif [4]. Therefore, YAP1 acts as a transcription co-activator of the Hippo-YAP signaling pathway together with PEBP2 $\alpha$ [5]. In addition, YAP1 
can co-activate other PPXY-motif-containing transcription factors such as receptor tyrosine-protein kinase erbB4 (ERBB4) and p73 [6]. YAP1 interacts with the transcription factors TEA domain transcription factors (TEAD)1-4 and plays an essential role in mediating TEAD-dependent gene expression, which are involved in cell proliferation and survival [7].

On a tumorigenesis point of view, YAP1 promotes epithelial-mesenchymal transition (EMT), which is involved in cancer metastasis [8]. YAP1 over-expression in transgenic mice induced a dramatic increase of liver size and finally led to tumors [9]. Furthermore, YAP1 (located on 11q22) has been identified as a candidate oncogene in several cancers; its overexpression and increased nuclear localization have been reported in breast cancer [8], hepatocellular carcinoma [10], colorectal cancer [11], GC [12], pancreatic cancer [13], and esophageal squamous cell carcinoma [14]. A recent study showed that YAP1 overexpression was associated with the progression, lymph node metastasis, and poor prognosis of GC [15]. Another study showed that YAP1 was highly expressed in GC tissues compared with normal tissues from the same patients, but that YAP1 did not correlate with the clinicopathologic characteristics of the patients [16]. Therefore, there remain some controversies about the role of YAP1 in GC.

The purposes of the present study were to detect the expression of YAP1 in GC specimens, and correlation with the prognosis of patients with $\mathrm{GC}$, to investigate the effects of stable YAP1 silencing and overexpression on the biological characteristics of GC and human immortalized normal gastric mucosa cells in vitro and in vivo, and to delineate the role of YAP1 in gastric tumorigenesis and progression.

\section{RESULTS}

\section{YAP1 and $\mathrm{P} 62$ protein expressions in GC specimens and paired non-tumor gastric mucosa, and correlation with the prognosis of patients with GC}

We assessed the YAP1 and P62 protein expressions by immunohistochemistry (IHC) in 302 GC specimens. YAP1 protein was located in the cytoplasm and nucleus. Compared with normal gastric mucosa, YAP1 expression was significantly up-regulated in moderately differentiated gastric adenocarcinoma, poorly differentiated adenocarcinoma, and signet ring cell cancer (Figure 1A-1D). Accordingly, compared with normal gastric mucosa, P62 expression was significantly up-regulated in moderately differentiated gastric adenocarcinoma, poorly differentiated adenocarcinoma, and signet ring cell cancer (Figure 1E-1H). YAP1 expression was high in 238 GC samples (78.8\%, $238 / 302$ ), which was significantly higher than in 64 GC samples with low expression $(21.2 \%, 64 / 302)(P<0.05)$. YAP1 expression was associated with Borrman's types $(P=0.041)$, WHO's histological types $(P=0.016)$, lymph node metastasis $(P<0.001)$, distant metastasis $(P<0.001)$, and TNM staging $(P<0.001)$, but was not associated with age, gender, Lauren's types, depth of invasion, and P62 expression (all $P>0.05$ ) (Table 1).

\section{YAP1 ${ }^{\text {high }}$ P62 ${ }^{\text {high }}$ expression was independently associated with poor prognosis of GC}

During the 107-month follow-up, 168 of 270 patients were known to be dead. The median survival was $51.8 \pm 2.7$ months. Kaplan-Meier curves showed that overall survival for patients with high-expression of YAP1 was significantly worse than for those with low expression $(P<0.001)$ (Figure 1I). Overall survival for patients with high-expression of P62 was significantly worse than for those in the low-expression group $(P=0.009)$ (Figure 1J). Overall survival for patients with YAP $1^{\text {high }} \mathrm{P} 62^{\text {high }}$ indicated the worst prognosis, compared with the other three groups $\left(P=0.005\right.$ vs. YAP1 ${ }^{\text {high }} \mathrm{P} 62^{\text {low}}$; $P<0.001 v s$. YAP $1^{\text {low }}$ P62 ${ }^{\text {high }} ; P<0.001 v s$. YAP1 $1^{\text {low }}$ P62 $\left.2^{\text {low }}\right)$ (Figure 1K). Furthermore, Kaplan-Meier analysis showed that Lauren's types, depth of invasion, lymph node metastasis, distant metastasis, and TNM staging were poor prognostic factors in GC (all $P<0.05$ ) (Table 2).

The multivariate Cox proportional hazards regression model 1 (did not include the combined variables (YAP1 and P62 expression, and Borrman and P62 expression)) showed that distant metastasis (hazard ratio (HR): $3.130,95 \%$ confidence interval (CI): 1.483-6.607, $P=0.003$ ) and TNM staging (HR: 2.964, 95\% CI: 1.741-5.044, $P=0.000)$ were independently associated with the prognosis of GC (Table 2). The multivariate Cox proportional hazards regression model 2 (did not include the individual variables (YAP1 protein expression and P62 protein expression)) showed that distant metastasis (HR: 2.817, 95\% CI: 1.328-5.978, $P=0.007$ ), TNM staging (HR: 2.923, 95\% CI: 1.711-4.995, $P<0.001$ ), YAP1 and P62 expression (HR: $1.334,95 \% \mathrm{CI}: 1.045-$ $1.704, P=0.021)$ were independent predictors of the prognosis of GC (Table 2).

\section{Effects of stable YAP1 silencing in BGC-823 cells and stable YAP1 overexpression in GES-1 cells on proliferation, clone formation ability, and cell cycle distribution in vitro}

YAP1 mRNA and protein expressions were higher in BGC-823 and SGC-7901 GC cells compared with human immortalized normal gastric mucosa GES-1 cells, but there was no YAP1 expression in MKN-45 GC cells (Figure 2A).

Stable YAP1 silencing (YAP1 short hairpin RNA (shRNA)) in BGC823 cells and stable YAP1 
overexpression in GES-1 cells were successfully established and validated by qRT-PCR and western blot. Expression of red fluorescence protein was observed in the vector BGC-823 group (BGC-823 cells stably transfected with pRFP-C-RS plasmid) and YAP1 shRNA BGC-823 group (BGC-823 cells stably transfected with pRFP-YAP1 shRNA), but not in the BGC-823 group (Figure 2B). Meanwhile, cells in the vector GES-1 group (GES-1 cells stably transfected with pEGFP-C3) and YAP1 GES-1 group (GES-1 cells stably transfected with pEGFP-C3YAP1 overexpression) expressed green fluorescence protein (Figure 2C). There was an obvious inhibition of YAP1 mRNA and protein expressions in the YAP1 shRNA BGC-823 group compared with the BGC-823 and vector BGC-823 groups (Figure 2D), and the mRNA and protein expressions of YAP1 in the YAP1 GES-1 group was higher than in the GES-1 and vector GES-1 groups (Figure 2E).

To understand whether YAP1 modulated proliferation and colony formation of GC and normal gastric mucosa cells, we performed 3-(4,5-dimethylthiazol-2-yl)-2,5diphenyltetrazolium bromide (MTT) and colony formation assays. As shown in Figure 2F, optical density (OD) values at $490 \mathrm{~nm}$ of the YAP1 shRNA BGC-823 group $(0.27 \pm$ $0.02,0.51 \pm 0.01,0.75 \pm 0.04)$ were significantly lower than those in the vector BGC-823 $(0.35 \pm 0.03,0.68 \pm 0.07$, $1.22 \pm 0.09)$ and BGC-823 $(0.36 \pm 0.03,0.71 \pm 0.04,1.29 \pm$ 0.11 ) groups (all $P<0.05$ ) from day 3 to day 5. Meanwhile, OD values at $490 \mathrm{~nm}$ of the YAP1 GES-1 group $(0.51 \pm$ $0.15,0.68 \pm 0.08,1.11 \pm 0.14)$ were significantly higher than those in the vector GES- $1(0.24 \pm 0.04,0.39 \pm 0.12$, $0.65 \pm 0.06)$ and GES- $1(0.27 \pm 0.08,0.42 \pm 0.09,0.68 \pm$ 0.08 ) groups (all $P<0.05$ ) from day 3 to day 5 .

The colony formation assay showed that the colonies in the YAP1 shRNA BGC-823 group were smaller and fewer than those formed in the vector BGC-823 and BGC-823 groups (Figure 2G). The number of colonies in the YAP1 shRNA BGC-823 group was reduced (both $P<0.05$, Figure 2I), but the GES- 1 cells transfected with
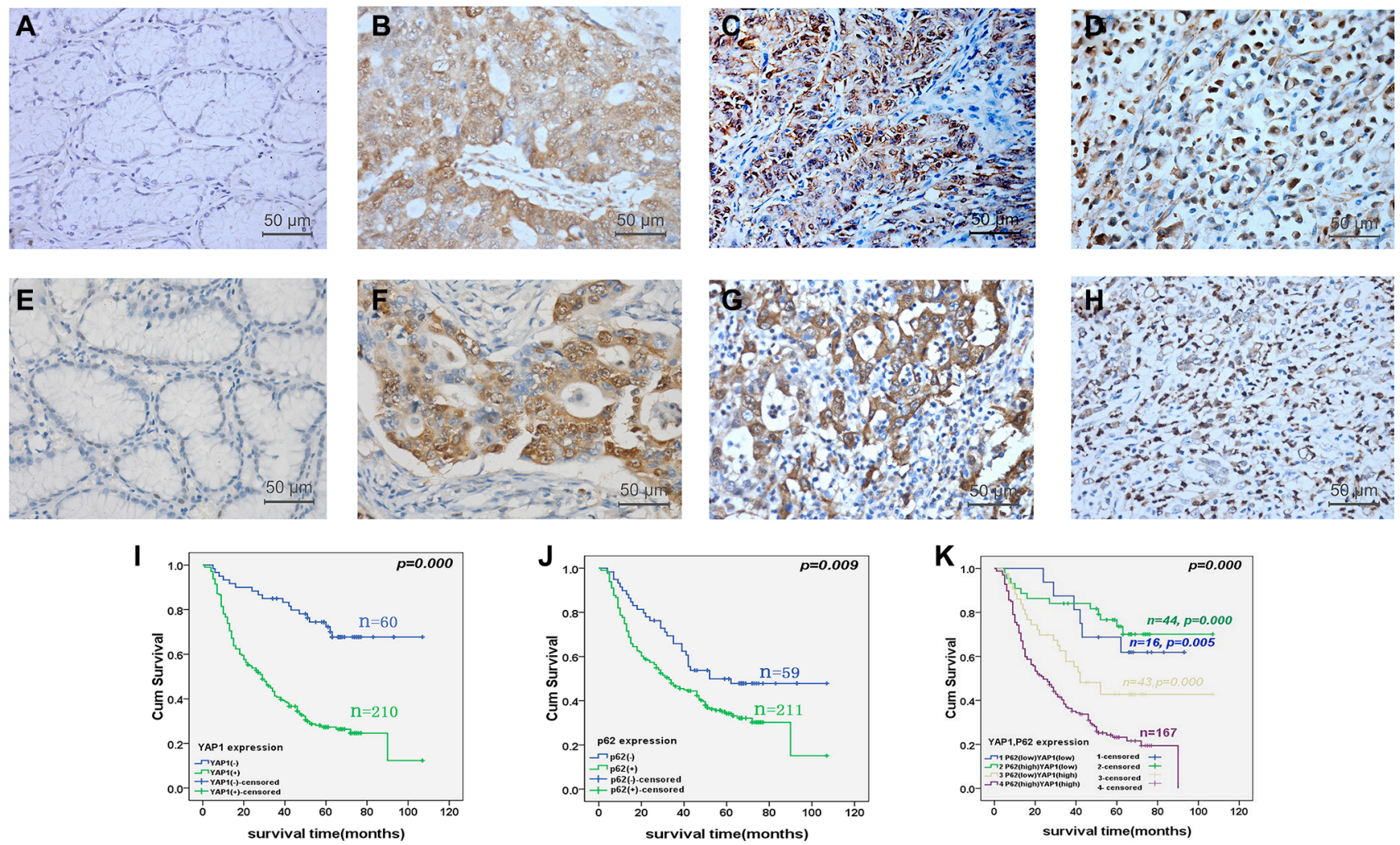

Figure 1: Yes-associated protein 1 (YAP1) and P62 protein expressions in gastric cancer (GC) specimens and paired non-tumor gastric mucosa, and correlation with the prognosis of patients with GC. YAP1 and P62 protein expression was determined by immunohistochemistry (magnification: $\times 400$ ). Compared with normal gastric mucosa $(\mathbf{A})$, YAP1 expression was significantly up-regulated in moderately differentiated gastric adenocarcinoma (B), poorly differentiated adenocarcinoma $(\mathbf{C})$, and signet ring cell cancer (D). Accordingly, compared with normal gastric mucosa (E), P62 expression was significantly up-regulated in moderately differentiated gastric adenocarcinoma $(\mathbf{F})$, poorly differentiated adenocarcinoma $(\mathbf{G})$, and signet ring cell cancer $(\mathbf{H})$. Kaplan-Meier curves were plotted to determine the cumulative survival rate of patients with GC based on YAP1 and P62 protein expression, and showed that overall survival for patients with YAP1 high-expression was significantly worse than for those with low expression $(P<0.001)$ (I). Overall survival for patients with P62 high-expression was significantly worse than for those in the P62 low-expression group $(P=0.009)(\mathbf{J})$. Overall survival for patients with YAP $1^{\text {high }} \mathrm{P} 62^{\text {high }}$ indicated the worst prognosis, compare with other three groups $\left(P=0.005 v s\right.$. YAP $1^{\text {high }} \mathrm{P} 62^{\text {low; }} ; P<0.001 v s$. YAP1 ${ }^{\text {low }}$ P62 ${ }^{\text {high }} ; P<0.001$ vs. YAP1 ${ }^{\text {low }}$ P6 $\left.2^{\text {low }}\right)(\mathbf{K})$. 
Table 1: Characteristics of the patients with gastric cancer

\begin{tabular}{|c|c|c|c|c|c|}
\hline \multirow{2}{*}{ Variable } & \multirow[b]{2}{*}{$n$} & \multicolumn{2}{|c|}{ YAP1 expression } & \multirow[b]{2}{*}{ HPR (\%) } & \multirow[b]{2}{*}{$P$} \\
\hline & & Low & High & & \\
\hline Age (year) & & & & & 0.927 \\
\hline$\leq 55$ & 110 & 23 & 87 & 79.1 & \\
\hline$>55$ & 192 & 41 & 151 & 78.6 & \\
\hline Gender & & & & & 0.387 \\
\hline Female & 86 & 21 & 65 & 75.6 & \\
\hline Male & 216 & 43 & 173 & 80.1 & \\
\hline Borrmann's types & & & & & 0.041 \\
\hline $\mathrm{I}+\mathrm{II}$ & 46 & 15 & 31 & 67.4 & \\
\hline $\mathrm{III}+\mathrm{IV}$ & 255 & 49 & 206 & 80.8 & \\
\hline WHO's histological types & & & & & 0.016 \\
\hline Papillary adenocarcinoma & 4 & 0 & 4 & 100 & \\
\hline Tubular adenocarcinoma & & & & & \\
\hline Well differentiated & 16 & 8 & 8 & 50 & \\
\hline Moderately differentiated & 67 & 16 & 51 & 76.1 & \\
\hline Poorly differentiated & 174 & 37 & 137 & 78.7 & \\
\hline Undifferentiated carcinoma & 4 & 0 & 4 & 100 & \\
\hline Signet ring cell adenocarcinoma & 7 & 1 & 6 & 85.7 & \\
\hline Mucinous adenocarcinoma & 30 & 2 & 28 & 93.3 & \\
\hline Lauren's types & & & & & 0.792 \\
\hline Intestinal & 92 & 18 & 74 & 80.4 & \\
\hline Diffuse & 161 & 34 & 127 & 78.9 & \\
\hline Mixed & 49 & 12 & 37 & 75.5 & \\
\hline Depth of invasion & & & & & 0.078 \\
\hline $\mathrm{T} 1+\mathrm{T} 2$ & 49 & 15 & 34 & 69.4 & \\
\hline $\mathrm{T} 3+\mathrm{T} 4$ & 253 & 49 & 204 & 80.6 & \\
\hline Lymph node metastasis & & & & & $<0.001$ \\
\hline No & 80 & 28 & 52 & 65 & \\
\hline N1-3 & 222 & 36 & 186 & 83.8 & \\
\hline Distant metastasis & & & & & $<0.001$ \\
\hline M0 & 213 & 60 & 153 & 71.8 & \\
\hline M1 & 89 & 4 & 85 & 95.5 & \\
\hline TNM staging & & & & & $<0.001$ \\
\hline $\mathrm{I}+\mathrm{II}$ & 112 & 39 & 73 & 65.2 & \\
\hline $\mathrm{III}+\mathrm{IV}$ & 190 & 25 & 165 & 86.8 & \\
\hline P62 expression & & & & & 0.088 \\
\hline Low & 66 & 19 & 47 & 71.2 & \\
\hline High & 236 & 45 & 191 & 80.9 & \\
\hline
\end{tabular}

YAP1: Yes-associated protein 1; HPR: High positive rate.

YAP1 overexpression showed increased colony formation compared with the GES-1 and vector GES-1 groups (both $P<0.05$, Figure $2 \mathrm{H}$ and $2 \mathrm{I}$ ).

Flow cytometry (FCM) using propidium iodide (PI) staining was used to access whether YAP1 modulated cell cycle distribution. Knockdown of YAP1 resulted in G0/G1 cell cycle arrest (BGC-823: $53.3 \pm 1.4 \%$; vector BGC-823:
$52.9 \pm 1.5 \%$; YAP1 shRNA BGC823: $62.1 \pm 1.6 \%$; both $P<0.05)$ and reduction of S phase cells in BGC-823 cells (Figure 2J and 2L). Accordingly, the percentages of cell in $\mathrm{G} 0 / \mathrm{G} 1$ phase of YAP1 GES-1 group $(36.6 \pm 0.7 \%)$ was significantly lower than that of the GES-1 $(45.4 \pm 0.8 \%)$ and vector GES-1 (44.2 $\pm 4.8 \%$ ) groups (both $P<0.05$, Figure $2 \mathrm{~K}$ and $2 \mathrm{~L}$ ). 
Table 2: Univariate and multivariate analysis of prognostic factors in 270 patients with gastric cancer

\begin{tabular}{|c|c|c|c|c|c|c|c|}
\hline \multirow{2}{*}{ Variable } & \multicolumn{3}{|c|}{ Univariate analysis $^{\mathrm{a}}$} & \multicolumn{2}{|c|}{ Multivariate analysis ${ }^{b}$} & \multicolumn{2}{|c|}{ Multivariate analysis ${ }^{c}$} \\
\hline & $n$ & Mean survival (months) & $\boldsymbol{P}$ & HR (95\% CI) & $\boldsymbol{P}$ & HR (95\% CI) & $\boldsymbol{P}$ \\
\hline Borrmann's types & & & 0.698 & & & & \\
\hline $\mathrm{I}+\mathrm{II}$ & 42 & 53.49 & & & & & \\
\hline $\mathrm{III}+\mathrm{IV}$ & 227 & 51.08 & & & & & \\
\hline WHO's histological types & & & 0.810 & & & & \\
\hline Papillary adenocarcinoma & 4 & 38.75 & & & & & \\
\hline Tubular adenocarcinoma & & & & & & & \\
\hline Well differentiated & 14 & 36.14 & & & & & \\
\hline Moderate differentiated & 57 & 54.68 & & & & & \\
\hline Poor differentiated & 159 & 49.49 & & & & & \\
\hline Undifferentiated carcinoma & 3 & 42.67 & & & & & \\
\hline Signet ring cell adenocarcinoma & 5 & 48.20 & & & & & \\
\hline Mucinous adenocarcinoma & 28 & 37.75 & & & & & \\
\hline Lauren's types & & & 0.032 & $1.063(0.846-1.336)$ & 0.599 & $1.081(0.861-1.358)$ & 0.501 \\
\hline Intestinal & 82 & 60.85 & & & & & \\
\hline Diffuse & 142 & 44.40 & & & & & \\
\hline Mixed & 46 & 44.57 & & & & & \\
\hline Depth of invasion & & & $<0.001$ & $0.770(0.403-1.471)$ & 0.428 & $0.828(0.432-1.588)$ & 0.570 \\
\hline $\mathrm{T} 1+\mathrm{T} 2$ & 44 & 79.72 & & & & & \\
\hline $\mathrm{T} 3+\mathrm{T} 4$ & 226 & 46.53 & & & & & \\
\hline Lymph node metastasis & & & $<0.001$ & $1.022(0.859-1.216)$ & 0.808 & $1.001(0.842-1.188)$ & 0.995 \\
\hline No & 74 & 75.80 & & & & & \\
\hline $\mathrm{N} 1-3$ & 196 & 41.99 & & & & & \\
\hline Distant metastasis & & & $<0.001$ & $3.130(1.483-6.607)$ & 0.003 & $2.817(1.328-5.978)$ & 0.007 \\
\hline M0 & 184 & 70.49 & & & & & \\
\hline M1 & 86 & 12.01 & & & & & \\
\hline TNM staging & & & $<0.001$ & $2.964(1.741-5.044)$ & $<0.001$ & $2.923(1.711-4.995)$ & $<0.001$ \\
\hline $\mathrm{I}+\mathrm{II}$ & 101 & 85.68 & & & & & \\
\hline III + IV & 169 & 31.85 & & & & & \\
\hline YAP1 protein expression & & & $<0.001$ & $0.794(0.563-1.121)$ & 0.190 & & \\
\hline Low & 60 & 83.73 & & & & & \\
\hline High & 210 & 41.90 & & & & & \\
\hline P62 protein expression & & & 0.009 & $1.221(0.813-1.833)$ & 0.337 & & \\
\hline Low & 59 & 65.99 & & & & & \\
\hline High & 211 & 46.63 & & & & & \\
\hline YAP1 and P62 expression & & & $<0.001$ & & & $1.334(1.045-1.704)$ & 0.021 \\
\hline YAP $1^{\text {low }}$ P6 $2^{\text {low }}$ & 16 & 72.87 & & & & & \\
\hline YAP $1^{\text {lowP }} 62^{\text {high }}$ & 44 & 84.69 & & & & & \\
\hline YAP $1^{\text {high }} \mathrm{P} 62^{\text {low }}$ & 43 & 60.27 & & & & & \\
\hline YAP $1^{\text {high }}$ P6 $2^{\text {high }}$ & 167 & 36.27 & & & & & \\
\hline Borrman and P62 expression & & & 0.017 & & & $1.004(0.839-1.202)$ & 0.964 \\
\hline Borrman I + II/p62 low & 25 & 51.83 & & & & & \\
\hline Borrman I + II/p62 high & 17 & 46.73 & & & & & \\
\hline Borrman III + IV/p62 & 185 & 64.06 & & & & & \\
\hline Borrman III + IV/p62 $2^{\text {high }}$ & 42 & 45.94 & & & & & \\
\hline
\end{tabular}

${ }^{a} \log$ rank test; ${ }^{\mathrm{b}} \mathrm{Cox}$ regression model (selected variables with $P$-values $<0.05$ in the univariate analyses were considered for inclusion in the regression model. Did not include the combined variables (YAP1 and P62 expression, and Borrman and P62 expression) ). ${ }^{\circ}$ Cox regression model (selected variables with $P$-values $<0.05$ in the univariate analyses were considered for inclusion in the regression model. Did not include the individual variables (YAP1 protein expression, and P62 protein expression)).

HR: hazard ratio; $95 \% \mathrm{CI}$ : $95 \%$ confidence interval. 

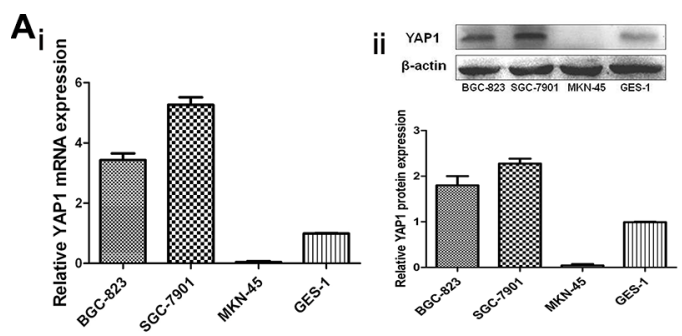

B
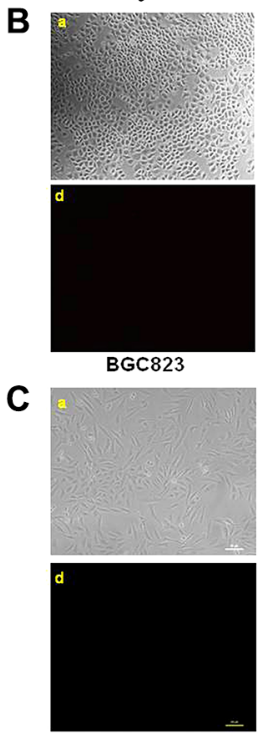

GES-1
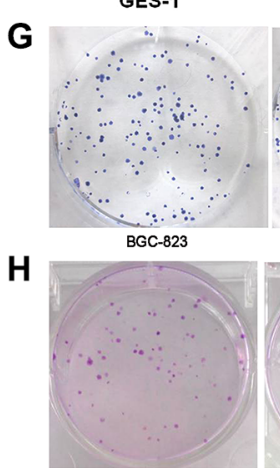

GES-1

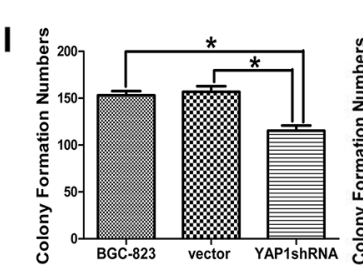

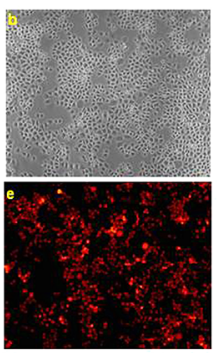

vector BGC-823
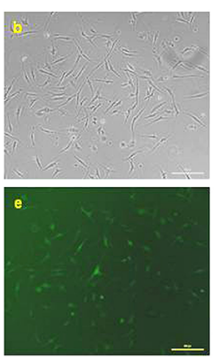

vector GES-1

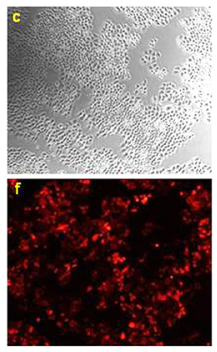

YAP1shRNA
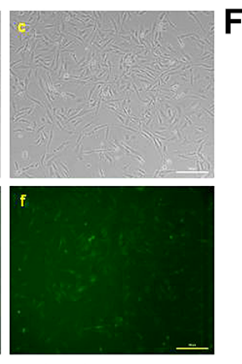

YAP1 GES-1

vector BGC-823
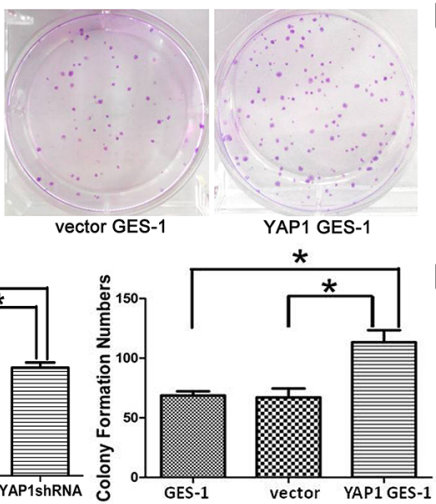

$\mathbf{E}_{i}$

J

K
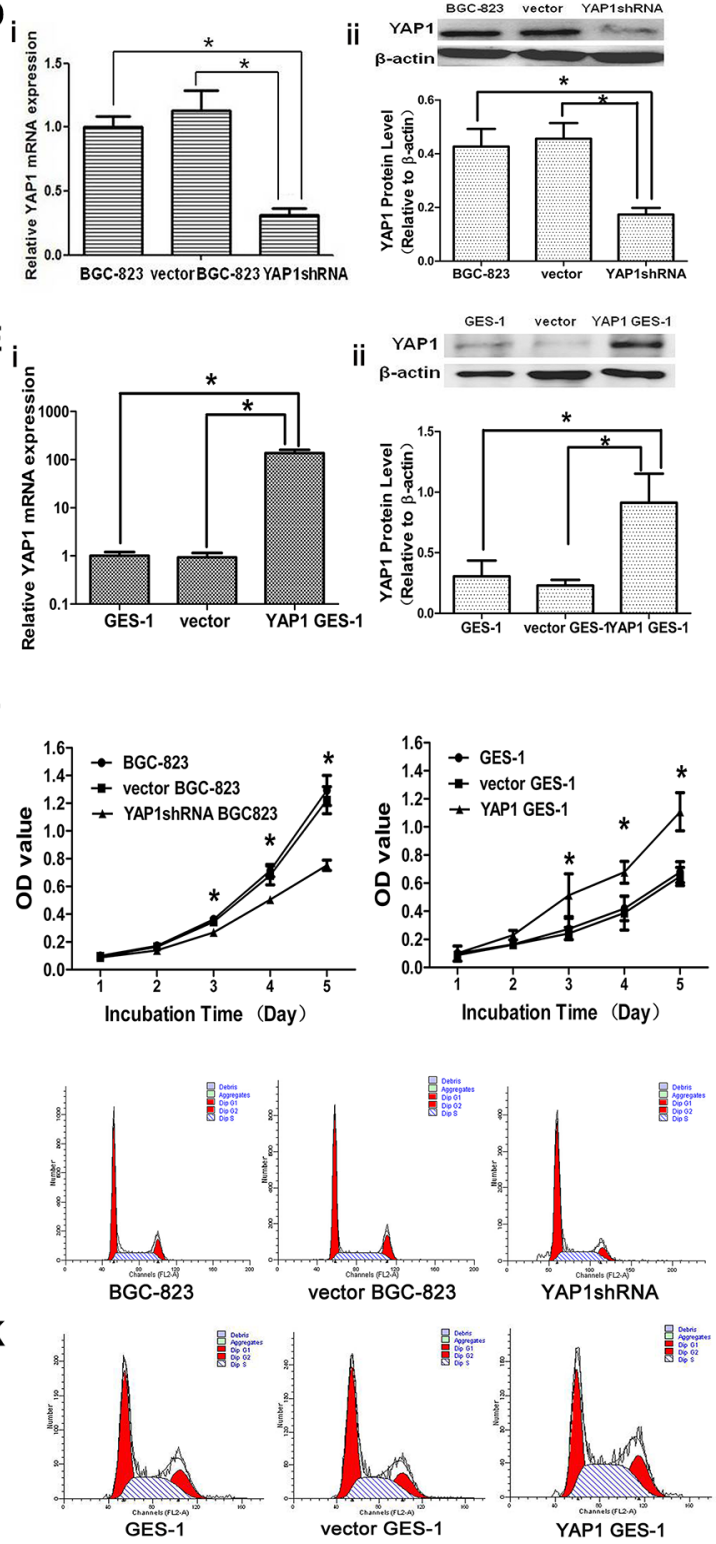

i) YAP1

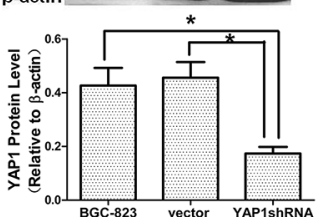

Incubation Time (Day)
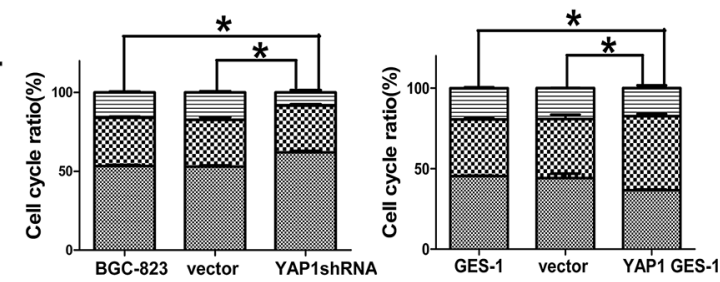

Figure 2: Effects of stable YAP1 silencing in BGC-823 cells and stable YAP1 overexpression in GES-1 cells on proliferation, clone formation ability, and cell cycle distribution in vitro. (A) YAP1 mRNA (i) and protein (ii) expression levels in the human GC cell lines BGC823, MKN45, and SGC7901, and the human immortalized normal gastric mucosa cell GES-1, as determined by qRT-PCR and western blot, respectively. BGC-823: untreated BGC-823 cells; Vector BGC-823: BGC-823 cells stably transfected with pRFP-C-RS plasmid; YAP1 shRNA: BGC-823 cells stably transfected with pRFP-YAP1 shRNA; GES-1: untreated GES-1 cells; Vector GES-1: GES-1 cells stably transfected with pEGFP-C3; and YAP1 GES-1: GES-1 cells stably transfected with pEGFP-C3YAP1 overexpression. (B) Expression of the red fluorescence protein (RFP) in the Vector BGC-823 (e) and YAP1 shRNA (f) groups under fluorescence microscope, but the RFP was not expressed in the BGC-823 group (d). (C) Expression of the green fluorescence protein (GFP) in vector GES-1 (e) and YAP1 GES-1 (f) groups under fluorescence microscope, but the GFP was not expressed in the GES-1 group (d). YAP1 mRNA (i) and protein (ii) expressions in BGC-823 (D) and GES-1 cells (E) as determined by qRT-PCR and western blot, respectively. (F) Cell proliferation in the BGC-823 and GES-1 cells was determined by MTT. Clone formation abilities in the BGC-823 cells $(\mathbf{G}, \mathbf{I})$ and GES-1 cells $(\mathbf{H}, \mathbf{I})$. Cell cycle distribution in the BGC-823 cells $(\mathbf{J}, \mathbf{L})$ and GES-1 cells $(\mathbf{K}, \mathbf{L})$ was determined by flow cytometry using propidium iodide (PI) staining. Data are shown as mean \pm standard deviation (SD). ${ }^{*} P<0.05$. 


\section{Effects of stable YAP1 silencing in BGC-823 cells and stable YAP1 overexpressing in GES-1 cells on migration and invasion abilities in vitro}

Wound-healing assay, Transwell migration, and invasion assay were performed to study the effect of YAP1 on the migration and invasion abilities of GC cells and normal gastric mucosa cells. As shown in Figure $3 \mathrm{~A}$ and $3 \mathrm{G}$, the wound healing rate of the YAP1 shRNA BGC-823 group $(8.3 \pm 0.5 \%, 23.4 \pm 1.7 \%, 45.0$ $\pm 4.8 \%)$ was decreased compared with that of the BGC$823(16.3 \pm 4.0 \%, 31.4 \pm 2.2 \%, 63.9 \pm 4.5 \%)$ and vector BGC-823 (18.3 $\pm 5.3 \%, 36.9 \pm 4.4 \%, 68.4 \pm 1.6 \%)$ groups at 24,48 , and $72 \mathrm{~h}$ (all $P<0.05$ ). On the other hand, the wound healing rate of the YAP1 GES1 group $(31.6 \pm 6.5 \%, 66.1 \pm 5.0 \%, 87.0 \pm 2.4 \%)$ was increased compared with that of the vector GES-1 (14.8 $\pm 2.5 \%$, $27.9 \pm 4.0 \%, 36.5 \pm 4.1 \%)$ and GES- $1(16.9 \pm 3.4 \%$, $29.5 \pm 1.7 \%, 38.2 \pm 2.7 \%$ ) groups at 24,48 , and $72 \mathrm{~h}$ (all $P<0.05$, Figure 3B and 3H).

The Transwell migration assay confirmed the results of the wound healing assay. After $24 \mathrm{~h}$ of incubation, knockdown of YAP1 led to a reduction of BGC823 cell migration capacity (Figure 3C and 3I), and YAP1 overexpression promoted cell migration ability of GES-1 cells (Figure 3D and 3J). The numbers of cells invading the Matrigel filter in the YAP1 shRNA BGC-823 group were less than that of the vector BGC-823 and BGC-823 groups (both $P<0.05$, Figure $3 \mathrm{E}$ and $3 \mathrm{~K}$ ). On the other hand, compared with the GES-1 and vector GES-1 groups, the number of cells invading the Matrigel filter in the YAP1 GES-1 group was significantly increased (both $P<0.05$, Figure $3 \mathrm{~F}$ and $3 \mathrm{~L}$ ).

\section{Effects of stable YAP1 silencing in BGC-823 cells and stable YAP1 overexpressing in GES-1 cells on the protein expressions of p-ERK1/2, ERK1/2, E-cadherin, vimentin, $\alpha$-catenin, and $\beta$-catenin, and LncRNA expressions including HOTAIR, H19, MALAT1, LATS2-AS1-001, and LATS2}

Western blotting showed that knockdown of YAP1 in the YAP1 shRNA BGC-823 group suppressed the protein expression of $\mathrm{p}-\mathrm{ERK} 1 / 2$ compared with the BGC-823 and vector BGC-823 groups (Figure 3M). EMT was inhibited, as shown by elevated E-cadherin protein expression and decreased vimentin protein expression in the YAP1 shRNA BGC-823 group compared with the BGC-823 and vector BGC-823 groups (Figure $3 \mathrm{M}$ ). Compared with the BGC-823 and vector BGC-823 groups, $\beta$-catenin protein expression in the YAP1 shRNA BGC-823 group was significantly down-regulated, while the expression of $\alpha$-catenin was obviously elevated (Figure 3M). In GES-1 cells, YAP1 overexpression significantly up-regulated the protein expression of $\mathrm{p}$-ERK1/2, vimentin, and $\beta$-catenin, and down-regulated the expression of E-cadherin and $\alpha$-catenin (Figure $3 \mathrm{M}$ ). It is well known that the expression of long non-coding RNA (LncRNA) plays critical roles in tumorigenesis. qRT-PCR showed that knockdown of YAP1 in the BGC-823 cells displayed down-regulated expressions of HOX transcript antisense RNA (HOTAIR), H19, metastasis-associated lung adenocarcinoma transcript 1 (MALAT1), human large tumor suppressor 2 (LATS2)-AS1-001, and LATS2 compared with the BGC-823 and vector BGC-823 groups (all $P<0.05$, Figure 3N, 3P, 3R, 3T, 3V and 3X). Accordingly, the expressions of HOTAIR, H19, MALAT1, LATS2-AS1-001 and LATS2 were elevated in GES-1 cells overexpressing YAP1 compared with the GES- 1 and vector GES- 1 groups (all $P<0.05$, Figures $3 \mathrm{O}, 3 \mathrm{Q}, 3 \mathrm{~S}, 3 \mathrm{U}, 3 \mathrm{~W}$ and $3 \mathrm{Y}$ ).

\section{Stable knockdown of YAP1 inhibited xenograft tumor growth and lung metastasis, but YAP1 was not related with tumorigenesis in vivo}

BALB/c-nude mice were injected subcutaneously into the right flanks with BGC-823, YAP1-shRNA BGC823, MKN45, GES-1, and GES-1-YAP1 cells, and let to grow for 4 weeks to establish the heterotopic xenograft tumor mice model. Results showed that silencing YAP1 significantly inhibited tumor growth. The tumor volume and tumor weight in the YAP1 shRNA BGC-823 group was smaller than those in the BGC-823 group (both $P<0.05$, Figure 4A, 4B, 4H and 4I). IHC showed that the YAP1 protein expression in the YAP1 shRNA BGC-823 group was lower than that in the BGC-823 group (Figure 4J and 4K). YAP1 mRNA levels in the YAP1 shRNA BGC-823 group was significantly lower than that in the BGC-823 group ( $P$ $<0.05$, Figure $4 \mathrm{M})$. All three mice in the MKN-45 group displayed tumors 28 days after cell inoculation (Figure 4C), but IHC showed that MKN-45 cells did not express YAP1 (Figure 4L). Mice injected subcutaneously with GES-1 cells and GES-1 cells overexpressing YAP1 did not generate tumors (Figure 4D and 4E). BGC-823 or YAP1shRNA BGC-823 cells were injected into nude mice through the tail vein. Stable knockdown of YAP1 reduced the number of lung metastases $(P<0.05$, Figure $4 \mathrm{~F}, 4 \mathrm{G}, 4 \mathrm{O}, 4 \mathrm{P}$, and $4 \mathrm{~N})$.

\section{DISCUSSION}

YAP1 is an effector of the Hippo pathway, which promoted cell proliferation and tumor growth in mammals $[17,18]$, but the influence of YAP1 in GC has not been comprehensively investigated. In the present study, the expression of YAP1 protein in GC tissues was elevated, which is supported by previous studies [15, 16]. Moreover, high-expression of YAP1 was associated with Borrman's types, WHO's histological types, lymph node metastasis, distant metastasis, and TNM staging. Hu et al. demonstrated that YAP1 overexpression was 
associated with progression, lymph node metastasis, and poor prognosis of GC, suggesting that overexpression of YAP1 could be a predictor of lymph node metastasis [15].

$\mathrm{P} 62$, encoded by proto-oncogene c-myc, is required for tumor transformation; P62 is overexpressed in several types of cancer [19, 20]. Qian et al. and Su et al. showed that P62 expression was common in gastrointestinal tract carcinomas and associated with cell differentiation and tumor metastasis $[21,22]$. In the present study, the multivariate COX regression analysis revealed that the YAP1 $1^{\text {high }}$ P62 ${ }^{\text {high }}$ expression pattern was independently associated with poor prognosis of patients with GC.
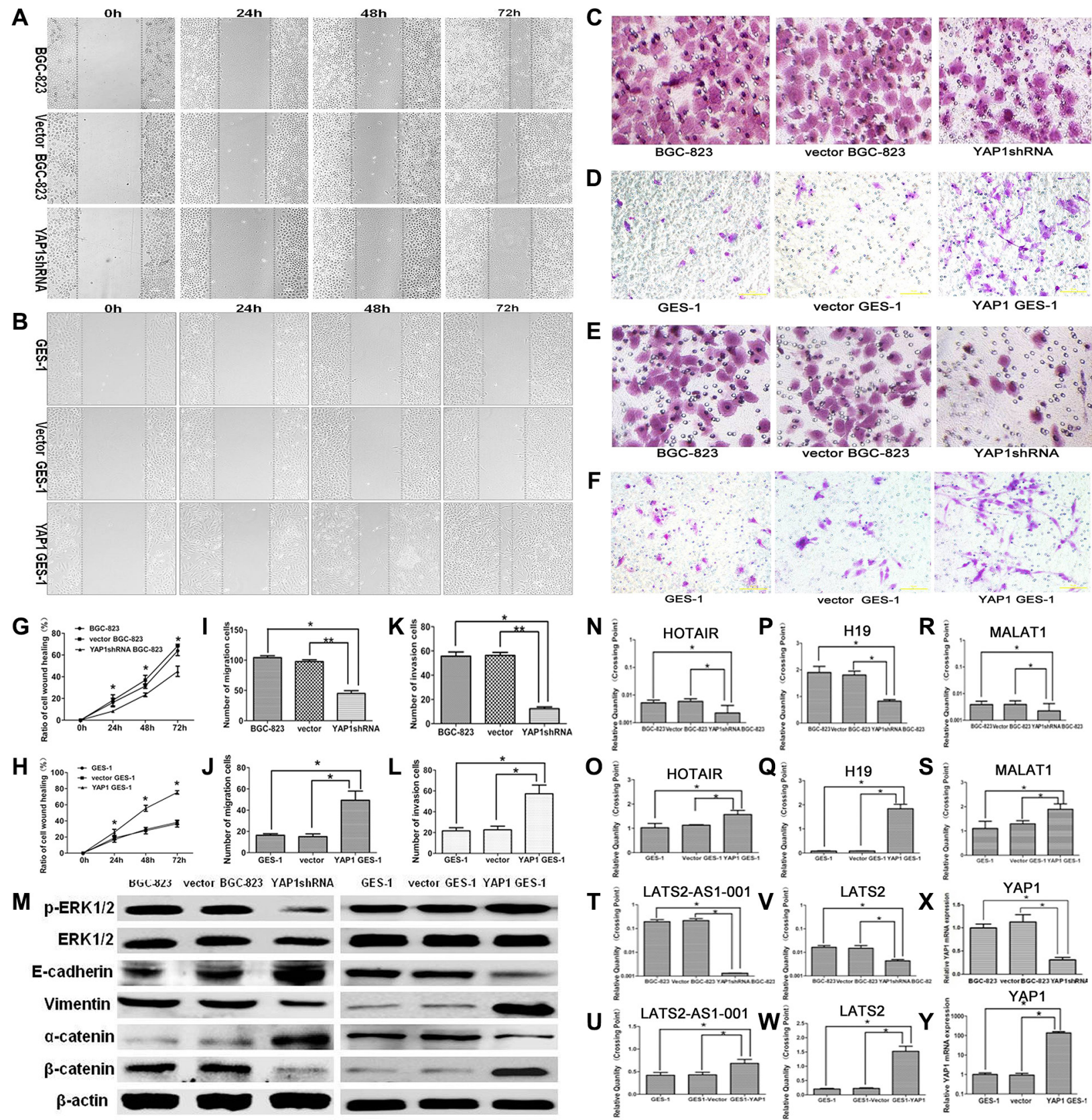

Figure 3: Effects of stable YAP1 silencing in BGC-823 cells and stable YAP1 overexpressing in GES-1 cells on migration and invasion abilities in vitro. The wound healing assay was used to evaluate the migration properties of BGC-823 GC cells (A, G) and GES-1 cells $(\mathbf{B}, \mathbf{H})$. Cells were photographed $0,24,48$, and $72 \mathrm{~h}$ after wounding (magnification $\times 100)$. The Transwell assay was used to evaluate the migration properties of BGC-823 GC cells $(\mathbf{C}, \mathbf{I})$ and GES-1 cells $(\mathbf{D}, \mathbf{J})$ (magnification: $\times 200)$. The Transwell assay was used to evaluate the invasion properties of BGC-823 GC cells $(\mathbf{E}, \mathbf{K})$ and GES-1 cells $(\mathbf{F}, \mathbf{L})$. (M) p-ERK1/2, ERK1/2, epithelial-related protein E-cadherin, mesenchymal related protein Vimentin, $\alpha$-catenin, and $\beta$-catenin expressions were determined by western blot. $\beta$-actin was used as an inner control. HOX transcript antisense RNA (HOTAIR) (N, O), H19 (P, Q), metastasis-associated lung adenocarcinoma transcript 1 (MALAT1) (R, S), human large tumor suppressor 2 (LATS2)-AS1-001 (T, U), and LATS2 (V, W) LncRNA expressions and YAP1 mRNA expression $(\mathbf{X}, \mathbf{Y})$ in BGC-823 and GES-1 cells were determined by qRT-PCR. Data are shown as mean $\pm \mathrm{SD} .{ }^{*} P<0.05 ; * * P<0.01$. 
To investigate the effect of YAP1 on the behavior of GC, we silenced the expression of YAP1 in BGC823 cells and overexpressed it in GES-1 cells. Downregulating YAP1 expression reduced the proliferation and colony formation ability of cells by suppressing the phosphorylation of ERK1/2, increasing the $\alpha$-catenin expression, and arrested the cells in G0/G1 phase. Inactive ERK $1 / 2$ is mostly located in the cytoplasm and transfers into the nucleus once activated to induce the transcription of cancer genes such as c-fos and c-myc [21, 22]. The sustained activation of ERK1/2 eventually promotes cell proliferation and malignant transformation. Elevated phosphorylated c-Raf/MEK1/2/ERK1/2 was observed in MKN45 cells stably expressing YAP1, and YAP1 expression could activate ERK1/2 signaling and resulted in c-fos induction [12]. Huo et al. demonstrated that the
A

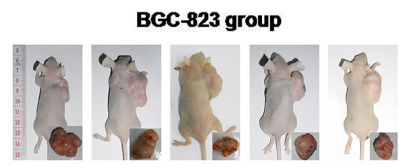

D

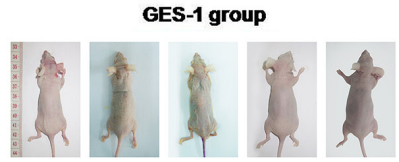

$\mathbf{F}$

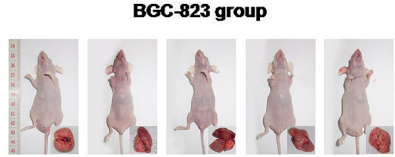

B

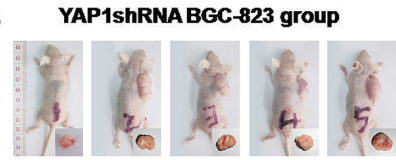

$\mathbf{E}$

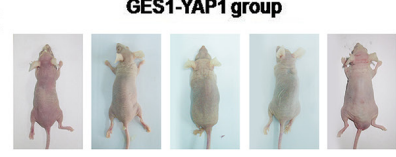

G

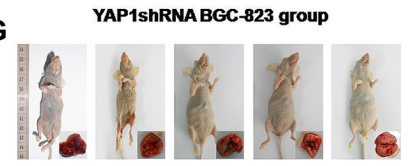

BGC-823 group
C MKN-45 group
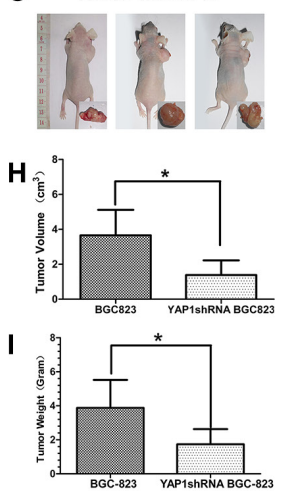

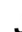
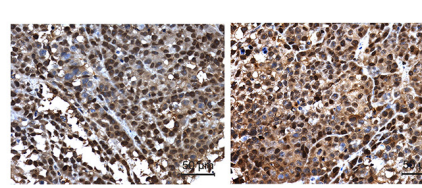

K

YAP1shRNABGC-823 group

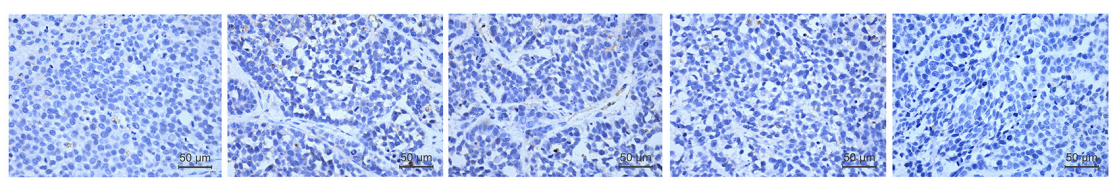

L MKN-45 group

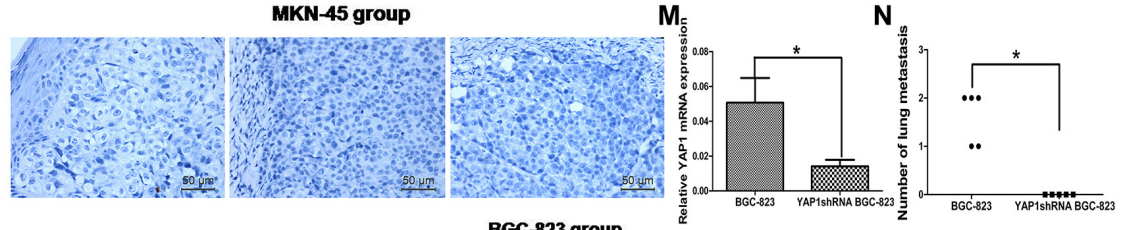

O

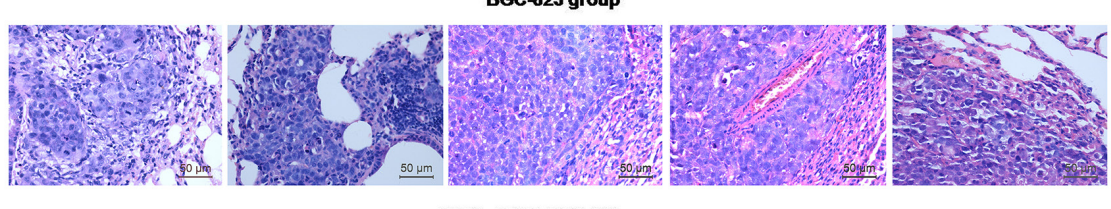

YAP1shRNABGC-823 group

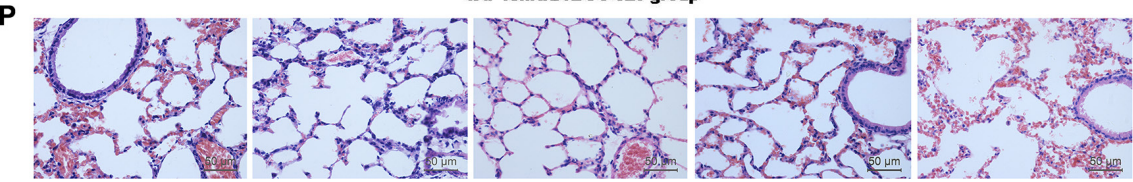

Figure 4: Stable knockdown of YAP1 inhibited xenograft tumor growth and lung metastasis, but YAP1 was not related with tumorigenesis in vivo. BALB/c-nude mice were injected subcutaneously into the right flanks with BGC-823 (A), YAP1-shRNA BGC-823 (B), MKN45 (C), GES-1 (D) and GES-1-YAP1 (E) cells, and let to grow for 4 weeks to establish the heterotopic xenograft tumor mice model. (H) Tumor volume and (I) tumor weight in BGC-823 and YAP1 shRNA BGC-823 groups. YAP1 protein expression was detected by immunohistochemistry (magnification: $\times 400)$ in BGC-823 (J), YAP1-shRNA BGC-823 (K) and MKN45 (L) groups. (M) YAP1 mRNA levels in BGC-823 and YAP1 shRNA BGC-823 groups were detected by qRT-PCR. Lung tissues and H\&E staining of lung sections (magnification: $\times 400$ ) in the BALB/c-nude mice hematogenous metastasis models that were harvested from the mice that had been injected in the lateral tail veins with BGC-823 (F, O) and YAP1 shRNA BGC-823 cells $(\mathbf{G}, \mathbf{P}), 8$ weeks after inoculation. (N) The numbers of metastatic foci per section of lung of individual mouse was measured after 8 weeks. $* P<0.05$. 
inhibition of YAP1 expression sensitized HCC cells to doxorubicin by decreasing the levels of phosphorylated ERK1/2 [23]. Furthermore, a previous study demonstrated that $\alpha$-catenin is a tumor suppressor that inhibits YAP1 activity and that YAP 1 is a key driver of keratinocyte proliferation induced by $\alpha$-catenin loss [24]. YAP1 acts downstream of $\alpha$-catenin to control epidermal proliferation [3]. $\alpha$-catenin depletion or deletion in keratinocytes relocalizes YAP1 from the cytoplasm to the nucleus [25]. Taken together with these previous studies, our results suggest that silencing YAP1 increase the expression of $\alpha$-catenin possibly by a negative feedback effect. In addition, the cell cycle results of the present study are consistent with those observed in different cancers (clear cell renal cell carcinoma [26], osteosarcoma [27], and GC [12]). It has been reported that accumulation of G1 cells was increased in MKN1 and AGS GC cells in which YAP1 expression was silenced [12]. Further analyses in 786-0 cells in which YAP1 is down-regulated demonstrated cell cycle G0/G1 arrest and inhibited cell proliferation [26].

Knockdown of YAP1 expression in SGC7901, MKN1, and AGS cells inhibited cell migration and invasion [12]. In the present study, the wound healing and Transwell assays showed that YAP1 could promote the cell migration and invasion abilities of GC in vitro. These effects could be attributed to promote EMT as shown by decreased epithelial-related protein E-cadherin expression and increased mesenchymal-related protein vimentin expression when YAP1 is overexpressed; on the other hand, using YAP1 shRNA, EMT was inhibited, as shown by elevated E-cadherin protein expression and decreased vimentin protein expression. Inducing EMT is a key feature of YAP signaling in mammalian tumor cells [28, 29], except in head and neck squamous cell carcinoma (HNSCC) [30] and non-small cell lung cancer (NSCLC) [31]. Zhang et al. found that over-expression of YAP1 in MCF10A cells resulted in the down-regulation of E-cadherin and concomitant up-regulation of $\mathrm{N}$-cadherin and fibronectin $[16,28]$. Loss of E-cadherin often induces the up-regulation of the $\beta$-catenin pathway [32] and the transcriptional activity of $\beta$-catenin is closely related to EMT $[33,34]$. Combined $\beta$-catenin and YAP1 silencing impairs the growth of human hepatoblastoma cells, while constitutively activated $\beta$-catenin and YAP1 trigger liver tumor development in mice [35]. Moreover, $\beta$-catenin is the cross point between Wnt and Hippo signaling pathways. YAP1 hinders $\beta$-catenin translocation to the nucleus and eventually suppresses Wnt signaling pathway [36, 37]. Consistent with these previous studies, our results showed that silencing YAP1 reduced the expression of $\beta$-catenin.

LncRNAs play important roles in tumorigenesis. HOTAIR is up-regulated in lung cancer, breast cancer, esophageal cancer, and GC [38]. HOTAIR is involved in the control of cell apoptosis, growth, metastasis, angiogenesis, DNA repair, and tumor cell metabolism [38]. Patients with high expression of HOTAIR have a poor prognosis [38]. In the present study, YAP1 overexpression increased the expression of HOTAIR. Up-regulation of H19 contributes to poor prognosis in patients with GC [39]. It was reported that YAP1 and H19 expression levels were elevated in bladder cancer cells, and H19 expression was found to be significantly associated with YAP1 expression [40]. In addition, YAP1 was found to enhance H19 expression, whereas H19 had no significant effect on YAP1 expression in bladder cancer [40]. Consistently, the present study found that YAP1 overexpression increased the expression of H19. MALAT1 is overexpressed in lung cancer, GC, and cervical cancer [41]. YAP1 up-regulates MALAT1 expression in liver cancer, whereas serine/arginine-rich splicing factor 1 (SRSF1) played an opposing role [41]. Consistently, we also observed that YAP1 overexpression increased the expression of MALAT1.

LATS2 plays a critical role in Hippo signaling [42]. YAP1 activation results in activation of their negative regulators, LATS1/2 kinases, to constitute a negative feedback loop of the Hippo pathway in both cultured cells and mouse tissues. YAP1 in complex with the transcription factor TEAD directly induce LATS2 expression. YAP1 also stimulate the kinase activity of LATS $1 / 2$ through inducing neurofibromin 2 (NF2) [43]. LATS2-AS1-001, a pseudogene transcript of LATS2 antisense RNA1 (LATS2AS1) has not been reported. In the present study, YAP1 overexpression significantly increased LATS1/2 and LATS2-AS1-001 expressions, suggesting that there was a negative feedback loop of the Hippo pathway.

Kang et al. showed that xenograft tumor growth induced by YAP1-expressing GC cells was significantly enhanced compared with control cells [12]. Similar results were shown in oral squamous cell carcinoma [44], human gallbladder cancer [45], osteosarcoma [27], esophageal cancer [46], cervical cancer [47], and ovarian cancer [48]. However, the present study suggests for the first time that YAP1 overexpression could promote tumor growth but do not affect tumorigenesis. Indeed, down-regulation of YAP1 in BGC-823 GC cells obviously reduced tumor growth in vivo. In addition, MKN-45 GC cells induced tumor formation despite having no YAP1 expression [12]. These evidences suggest that YAP1 expression is not a direct factor affecting tumor formation, but that YAP1 over-expression could accelerate tumor cell growth. Song et al. suggested that YAP1 was able to confer cancer stem cell properties onto a wide variety of non-transformed cell types of gastrointestinal origin, including primary isolated esophageal epithelium cells, immortalized embryonic liver cells, and esophageal cancer cells [46]. In the present study, GES-1 cells (human immortalized normal gastric mucosa cells) were selected to overexpress YAP1 to examine whether YAP1 has an effect of tumoriginesis. The results showed that both GES-1 and YAP1-overexpressing GES-1 cells inoculated into mice could not form tumor, suggesting that the YAP1 gene might not involve in tumorigenesis. So far, this finding has not been reported. 
Finally, the present study is the first to report that silencing YAP1 in BGC-823 GC cells significantly suppressed hematogenous metastatic spread of tumor cells. The tail vein injection model is known to have some disadvantages. Indeed, the cells do not follow the biological steps of metastasis formation [49] and ignore the crosstalk between the primary and metastatic tumors [50]. Although we agree that the tail vein injection model is not perfect to mimic the metastasis of cancer, it could nevertheless provide some clues about the metastatic and invasive abilities of cancer cells, when the cells are considered as having detached themselves from the primary tumor [51]. A recent study showed that the tail vein injection model was equivalent to the orthotopic injection model [52]. Nevertheless, additional study is necessary to further address the potential role of YAP1 in migration/invasion in vivo, since there is a possibility that reduced tumor expansion in the lung was due to YAP1 role in inhibiting the cell cycle that contributed to the observation.

In summary, elevated expression of YAP1 was observed in GC and was associated with the progression and metastasis of GC, and YAP1 $1^{\text {high }}$ P62 $2^{\text {high }}$ expression pattern were independently associated with poor prognosis of patients with GC. Furthermore, YAP1 effectively promoted the proliferation, colony formation, migration, and invasion of BGC-823 GC cells and human immortalized normal gastric mucosa GES-1 cells in vitro. The mechanism was associated with EMT, ERK1/2, $\alpha$-catenin, and $\beta$-catenin, and with lncRNAs including HOTAIR, H19, MALAT1, LATS2-AS1-001, and LATS2. In addition, stable knockdown of YAP1 inhibited xenograft tumor growth and lung metastasis, but YAP1 was not related to tumorigenesis in vivo. Taken together, these findings suggest that YAP1 could be a potential target for GC therapy.

\section{MATERIALS AND METHODS}

\section{Clinical specimens}

Surgically resected GC specimens $(n=302)$ and paired non-tumor gastric mucosa (PNTG) (collected $>5 \mathrm{~cm}$ away from the edge of the primary tumor) were collected from August 2007 to October 2012 at the First Affiliated Hospital of China Medical University. None of the patients had received chemotherapy or radiotherapy before surgery. The characteristics of the patients are shown in Table 1. The study was approved by the Clinical Research Ethics Committee of the First Affiliated Hospital of China Medical University. Written informed consent was obtained from all study participants.

\section{Immunohistochemistry}

Tissue microarrays of $\mathrm{GC}$ and gastric mucosa were constructed, and then cut to $4-\mu \mathrm{m}$ sections. IHC for YAP1 and P62 was performed according to the manufacturer's instructions using rabbit anti-human
YAP1 polyclonal antibody (1:100; Cell signaling; \#4912) and mouse anti-human p62 polyclonal antibody (1:500; MBL; M162-3). Phosphate-buffered saline (PBS) was used as negative control.

YAP1 or P62 positivity was defined as the clear presence of brown granules in cytoplasm or nuclei and was assessed by two independent experienced pathologists blinded to the characteristics of the patients. The score was made according to the proportion of positive cells $(0$, none; $1, \leq 10 \% ; 2,11-25 \% ; 3,26-50 \% ; 4,>50 \%)$. The intensity score was assigned for the average intensity of positive cells ( 0 , none; 1 , weak; 2 , intermediate; 3 , strong). The final score was the product of the two subscores, ranging $0-12$. The expression was categorized as negative (score 0), (-); low (score 1-3), (1+); intermediate (score 4-6), (2+); and high (score 7-12), (3+). Patients were classified into two groups: scores $0-1+$ were considered as low expression, while $2+-3+$ were considered as high expression.

\section{Cell culture}

The human GC cell lines BGC823, MKN45, and SGC7901, and the human immortalized normal gastric mucosa cell GES-1 were obtained from the Cancer Research Institution of China Medical University (China). The cells were cultured in RPMI-1640 (Hyclone, Logan, USA) supplemented with 10\% fetal bovine serum (FBS) (Hyclone, Logan, USA) and 1\% penicillin-streptomycin (Solarbio, Beijing, China), and incubated in $5 \% \mathrm{CO}_{2}$ at $37^{\circ} \mathrm{C}$.

\section{YAP1 silencing/overexpressing in cell lines}

After preliminary experiment (two sequences were identified as specific YAP1-shRNA targeted sequences), the pRFP-YAP1 shRNA targeting sequence of human YAP1 gene (Genbank No. NM_001130145.2) (5'GAT Ccc aga gaa tca gtc aga gaT TCA AGA Gat ctc tga ctg att ctc tgg TTT TTT A-3') was chosen for the subsequent experiments. The non-coding plasmid pRFPC-RS (Origene, USA) was used as a negative control. The plasmids for pEGFP-C3 and pEGFP C3-YAP1 overexpression were purchased from Addgene Co. The pRFP-YAP1 shRNA and pRFP-C-RS plasmids were transfected into BGC-823 GC cells. The pEGFP-C3 and pEGFP-C3-YAP1 plasmids were transfected into GES-1 cells. All plasmids were transfected into cells using Lipofectamine $^{\mathrm{TM}} 2000$ (Invitrogen, Carlsbad, USA), according to manufacturer's instructions.

Stable YAP1 shRNA BGC-823 and negative control cells (Vector BGC-823) were selected by puromycin. Stable YAP1 GES-1 and negative control cells (Vector GES-1) were selected by G418. All clones were picked out by fluorescence microscopy (Nikon eclipse Ti-s, Nikon Digital sight DS-U3) and cultured for at least 6 weeks before confirming the expression of YAP1 by qRT-PCR and western blotting. 


\section{Quantitative real-time reverse transcriptase -PCR}

Total RNA was isolated using the EASYspin Plus kit (Aidlab Biotechnologies, Beijing, China), according to the manufacturer's instructions. Isolated RNA was reversetranscribed to cDNA with the PrimeScript ${ }^{\mathbb{R}}$ RT reagent kit (TaKaRa, Dalian, China). Primer sequences were: YAP1 sense, 5'-TAC GAT ACA AGG CTG TTA GAG AG-3' and anti-sense, 5'-TTG AGA TGC ATG CTT TGC ATA C-3'; GAPDH sense, 5'-GAA GGT GAA GGT CGG AGT C-3' and antisense, 5'-GAA GAT GGT GAT GGG ATT TC-3'; HOTAIR sense, 5'-ggT AgA AAA AgC AAC CAC gAA gC-3' and anti-sense, 5'-ACA TAA ACC TCT gTC TgT gAg TgC C-3'; H19 sense, 5'-ACT CAg gAA TCg gCT CTg gAA-3' and anti-sense, $5^{\prime}$-CTg CTg TTC CgA Tgg TgT CTT-3'; MALAT1 sense, 5'-TAg gAA gAC AgC $\mathrm{AgC} \mathrm{AgA} \mathrm{CA} \mathrm{gg-3'} \mathrm{and} \mathrm{anti-sense} \mathrm{5'-TTg} \mathrm{CTC} \mathrm{gCT} \mathrm{TgC}$ TCC TCA gT-3'; LATS2-AS1-001 sense, 5'-CTC TGG CAC TCC TAC T-3' and anti-sense, 5'-CTG GAC CTG AAC CTA C-3'; and LATS2 sense, 5'-AGC TGG ACT CTG TGA AGC TG-3' and anti-sense 5'-TGT CCA CCT TAC AAG CAA GG-3'. The PCR reaction was performed in $10 \mu 1$, including each primer, diluted cDNA templates, and SYBR ${ }^{\circledR}$ Premix TaqTM II (TaKaRa, Dalian, China). The conditions were: 1) $95^{\circ} \mathrm{C}$ for $30 \mathrm{~s}$; and 2) 40 cycles of $95^{\circ} \mathrm{C}$ for $5 \mathrm{~s}$, annealing at $58.5^{\circ} \mathrm{C}$ for $30 \mathrm{~s}$; dissolving curve at $95^{\circ} \mathrm{C}$ for $15 \mathrm{~s}, 60^{\circ} \mathrm{C}$ for $30 \mathrm{~s}$, and $95^{\circ} \mathrm{C}$ for $15 \mathrm{~s}$. The data was calculated using the $2^{-\Delta \Delta \mathrm{Ct}}$ method, normalized to GAPDH. Each cDNA sample was run in triplicate.

\section{Western blotting}

Cells were lyzed with a lysis buffer containing phenylmethyl sulfonylfluoride (PMSF) (Beyotime, Shanghai, China) at $4^{\circ} \mathrm{C}$. Proteins were quantified using a BCA protein assay kit (ComWin Biotech, Beijing, China). Protein lysates $(50 \mu \mathrm{g})$ were separated by $10 \%$ SDS-PAGE gels (Invitrogen) and transferred onto a polyvinylidene difluoride (PVDF) membrane (Beyotime, Shanghai, China). The membranes were blocked with $5 \%$ non-fat dry milk in Tris-phosphate buffer containing $0.05 \%$ Tween 20 (TBS-T) for $1 \mathrm{~h}$ at room temperature and then treated with the primary antibodies at $4^{\circ} \mathrm{C}$ overnight. After washing with TBST, the membranes were incubated with peroxidase-conjugated affinipure goat anti-rabbit $\operatorname{IgG}$ $(\mathrm{H}+\mathrm{L})$ (ZSGB-BIO, 1:5000, ZB-2301) and peroxidaseconjugated affinipure goat anti-mouse $\mathrm{IgG}(\mathrm{H}+\mathrm{L})$ (ZSGBBIO, 1:5000, ZB-2305) for $1 \mathrm{~h}$ at room temperature. The blots were visualized using an ECL kit (ComWin Biotech, Beijing, China), and quantified using the Image J Software, normalized to $\beta$-actin. The primary antibodies were: E-cadherin (1:500, Cell signaling, \#3195), Vimentin (1:1000, Cell signaling, \#5741), ERK1/2 (1:1000, Cell signaling; \#4695), p-ERK1/2 (Thr202/Tyr204) (1:1000, Cell signaling, \#9101), $\alpha$-catenin (1:500, Proteintech, Catalog number: 66221-1-Ig), $\beta$-catenin (1:1000, Santa Cruz, sc-7963), and $\beta$-actin (1:1000, Bioss).

\section{Cell proliferation and colony formation assays}

Cells were plated in 96-well plates at $2 \times 10^{3}$ cells per well. MTT assays were performed every day over the following 5 days. Cells were incubated for $4 \mathrm{~h}$ in $20 \mu \mathrm{L}$ MTT (Sigma, USA) $(0.5 \mathrm{mg} / \mathrm{ml})$ at $37^{\circ} \mathrm{C}$. The color was developed by incubating the cells in $150 \mu \mathrm{L}$ dimethylsulfoxide (DMSO, Sigma) and the plates were gently shaken for $10 \mathrm{~min}$. The absorbance was detected at $490 \mathrm{~nm}$.

For the colony formation assay, cells were cultured in six-well plates at 200 cells/well. After 12 days, the cells were fixed in 4\% paraformaldehyde and stained with Giemsa (Sigma, USA). Colonies were then photographed under a Nikon eclipse Ti-S microscope (Nikon, Japan) and scored.

\section{Cell cycle}

Cells were washed twice with cold PBS, fixed in $70 \%$ ethanol at $4^{\circ} \mathrm{C}$ for $24 \mathrm{~h}$, and stained with $0.05 \mathrm{mg} / \mathrm{ml}$ of PI (Beyotime, Shanghai, China) and $0.05 \mathrm{mg} / \mathrm{ml}$ of RNase A (Beyotime, Shanghai, China) for $30 \mathrm{~min}$ in the dark. The cells were analyzed using a FACSCalibur (BD, USA).

\section{Wound healing assay}

Cells were seeded into 6 -well plates at $3 \times 10^{5}$ cells/ well. When reached $90 \%$ confluence, a single wound was created in the center of the well with a $10-\mu 1$ sterile plastic tip. After washing the well with PBS, the cells migrating into the wounded areas were visualized and photographed at $0,24,48$, and $72 \mathrm{~h}$. The cell wound healing rate was calculated to assess cell mobility.

\section{Transwell migration and invasion assays}

The cell migration assay was performed using a 24-well Transwell polycarbonate filters $(8-\mu \mathrm{m}$ pore size, Corning, USA). The cells were trypsinized and added to the upper chamber in $200 \mu \mathrm{l}$ of serum-free medium containing $2 \times 10^{5}$ cells, while the lower chamber contained $500 \mu \mathrm{l}$ of RPMI-1640 supplemented with $20 \%$ fetal FBS. After incubating for $24 \mathrm{~h}$, the cells passing through the filter were fixed with $4 \%$ paraformaldehyde, stained with $1 \%$ crystal violet, and counted under a Nikon eclipse Ti-S microscope.

For the cell invasion assay, the Transwell chambers were coated with $200 \mu \mathrm{l}$ of Matrigel at a dilution of 1:7 in serum-free medium and the incubation time was extended to $48 \mathrm{~h}$. The remaining of the methods was same as for the cell migration assay.

\section{Heterotopic xenograft tumor model and hematogenous metastasis model}

Four-week old female BALB/c-nude mice were purchased from Beijing Vital River Laboratory Animal Co., Ltd., China. All animals were maintained under a sterile environment at the Animal Laboratory Unit of the 
China Medical University. The animals were grouped: BGC-823, BGC-823 stably transfected with pRFP-YAP1 shRNA, MKN45 (which do not express YAP1) [12], GES1 , and GES-1 cells stably transfected with pEGFP C3YAP1 overexpression. After resuspension in PBS, $5 \times 10^{6}$ cells in $200 \mu \mathrm{L}$ were injected subcutaneously into the right flanks of the nude mice. Tumor volume was measured weekly using a digital caliper according to the formula: TV $\left(\mathrm{mm}^{3}\right)=$ length $\times$ width $^{2} \times 0.5$. All the mice were sacrificed 4 weeks after cell inoculation. Tumors were excised, photographed, measured, and weighted. IHC and qRT-PCR was used to assess the RNAi efficiency in vivo.

For the hematogenous metastasis model, BGC823 cells and BGC823 cells stably transfected with pRFPYAP1 shRNA were collected in the logarithmic growth phase and inoculated into the tail vein at $5 \times 10^{6} / 100$ $\mu \mathrm{L}$. Eight weeks later, the mice were sacrificed. H\&E staining was used to detect lung metastasis.

All procedures and animal experiments were approved by the Animal Care and Use Committee of the First Affiliated Hospital of China Medical University.

\section{Statistical analysis}

Statistical analysis was performed using SPSS 17.0 (IBM, Armonk, NY, USA). Categorical data were presented using proportion and compared with the chisquare test or the Fisher's exact test, as appropriate. All quantitative data were expressed as mean \pm standard deviation and analyzed using the Student's $t$-test or one-way ANOVA with Bonferroni as post hoc test, as appropriate. The Kaplan-Meier and log-rank tests were used for survival analysis. Multivariable analysis model was run using a Cox proportional hazards regression model (enter method). All statistical analyses were twosided, and significance was assigned at $\alpha=0.05$.

\section{ACKNOWLEDGMENTS AND FUNDING}

This work was supported by the National Natural Science Foundation of China (No.81071650 and 30973503), the Special Foundation for Science and Technology Program in Liaoning Province, China (2013225303-103 and 2011404013-3), and the Supporting Project for Climbing Scholars in Liaoning Provincial Universities, China (2009-2012).

\section{CONFLICTS OF INTEREST}

All authors confirm that there are no conflicts of interest to declare.

\section{REFERENCES}

1. Zhou C, Ji J, Cai Q, Shi M, Chen X, Yu Y, Liu B, ZhuZ, Zhang J. MTA2 promotes gastric cancer cells invasion and is transcriptionally regulated by Sp1. Mol Cancer. 2013; 12:102.

2. Marrelli D, Morgagni P, de Manzoni G, Coniglio A, Marchet A, Saragoni L, Tiberio G, Roviello F and Italian Research Group for Gastric C. Prognostic value of the 7th AJCC/UICC TNM classification of noncardia gastric cancer: analysis of a large series from specialized Western centers. Ann Surg. 2012; 255:486-491.

3. Schlegelmilch K, Mohseni M, Kirak O, Pruszak J, Rodriguez JR, Zhou D, Kreger BT, Vasioukhin V, Avruch J, BrummelkampTR, Camargo FD. Yap1 acts downstream of alpha-catenin to control epidermal proliferation. Cell. 2011; 144:782-795.

4. Macias MJ, WiesnerS, Sudol M. WW and SH3 domains, two different scaffolds to recognize proline-rich ligands. FEBS Lett. 2002; 513:30-37.

5. Yagi R, Chen LF, Shigesada K, MurakamiY, Ito Y. A WW domain-containing yes-associated protein (YAP) is a novel transcriptional co-activator. EMBO J. 1999; 18:2551-2562.

6. Strano S, Monti O, Pediconi N, Baccarini A, Fontemaggi G, Lapi E, Mantovani F, Damalas A, Citro G, Sacchi A, Del Sal G, LevreroM, Blandino G. The transcriptional coactivator Yes-associated protein drives p73 gene-target specificity in response to DNA Damage. Mol Cell. 2005; 18:447-459.

7. LeeKK, Yonehara S. Identification of mechanism that couples multisite phosphorylation of Yes-associated protein (YAP) with transcriptional coactivation and regulation of apoptosis. J Biol Chem. 2012; 287:9568-9578.

8. Overholtzer M, Zhang J, Smolen GA, Muir B, Li W, Sgroi DC, Deng CX, BruggeJS, Haber DA. Transforming properties of YAP, a candidate oncogene on the chromosome 11q22 amplicon. Proc Natl Acad Sci USA. 2006; 103: 12405-12410.

9. Camargo FD, Gokhale S, Johnnidis JB, Fu D, Bell GW, JaenischR, Brummelkamp TR. YAP1 increases organ size and expands undifferentiated progenitor cells. Curr Biol. 2007; 17:2054-2060.

10. Tschaharganeh DF, Chen X, Latzko P, Malz M, Gaida MM, Felix K, Ladu S, Singer S, Pinna F, Gretz N, Sticht C, Tomasi ML, Delogu S, et al. Yes-associated protein upregulates Jagged-1 and activates the Notch pathway in human hepatocellular carcinoma. Gastroenterology. 2013; 144:1530-1542 e1512.

11. Yuen HF, McCrudden CM, Huang YH, Tham JM, Zhang X, Zeng Q, ZhangSD, Hong W. TAZ expression as a prognostic indicator in colorectal cancer. PloS one. 2013; 8:e54211.

12. Kang W, Tong JH, Chan AW, Lee TL, Lung RW, Leung PP, So KK, Wu K, Fan D, Yu J, SungJJ, To KF. Yes-associated protein 1 exhibits oncogenic property in gastric cancer and its nuclear accumulation associates with poor prognosis. Clin Cancer Res. 2011; 17:2130-2139.

13. Diep CH, Zucker KM, Hostetter G, Watanabe A, Hu C, Munoz RM, Von HoffDD, Han H. Down-regulation of Yes Associated Protein 1 expression reduces cell proliferation 
and clonogenicity of pancreatic cancer cells. PloS one. 2012; 7:e32783.

14. Muramatsu T, Imoto I, Matsui T, Kozaki K, Haruki S, Sudol M, Shimada Y, Tsuda H, KawanoT, Inazawa J. YAP is a candidate oncogene for esophageal squamous cell carcinoma. Carcinogenesis. 2011; 32:389-398.

15. $\mathrm{Hu} \mathrm{X}, \mathrm{Xin} \mathrm{Y}, \mathrm{XiaoY}$, Zhao J. Overexpression of YAP1 is correlated with progression, metastasis and poor prognosis in patients with gastric carcinoma. Pathol Oncol Res. 2014; 20:805-811.

16. Zhang J, Yang YC, Zhu JS, ZhouZ, Chen WX. Clinicopathologic characteristics of YES-associated protein 1 overexpression and its relationship to tumor biomarkers in gastric cancer. Int J Immunopathol Pharmacol. 2012; 25:977-987.

17. Sun Z, Xu R, Li X, Ren W, Ou C, Wang Q, Zhang H, Zhang X, Ma J, WangH, Li G. Prognostic Value of YesAssociated Protein 1 (YAP1) in Various Cancers: A MetaAnalysis. PloS one. 2015; 10:e135119.

18. WierzbickiPM, Rybarczyk A. The Hippo pathway in colorectal cancer. Folia Histochem Cytobiol. 2015; 53:105-119.

19. MoscatJ, Diaz-Meco MT. p62: a versatile multitasker takes on cancer. Trends Biochem Sci. 2012; 37:230-236.

20. Li Y, FranciaG, Zhang JY. p62/IMP2 stimulates cell migration and reduces cell adhesion in breast cancer. Oncotarget. 2015; 6:32656-32668. doi: 10.18632/ oncotarget.5328.

21. Qian HL, Peng XX, Chen SH, YeHM, Qiu JH. p62 Expression in primary carcinomas of the digestive system. World J Gastroenterol. 2005; 11:1788-1792.

22. Su Y, Qian H, Zhang J, Wang S, ShiP, Peng X. The diversity expression of p62 in digestive system cancers. Clin Immunol. 2005; 116:118-123.

23. Huo X, Zhang Q, Liu AM, Tang C, Gong Y, Bian J, Luk JM, $\mathrm{Xu} \mathrm{Z}$, Chen J. Overexpression of Yes-associated protein confers doxorubicin resistance in hepatocellullar carcinoma. Oncol Rep. 2013; 29:840-846.

24. Silvis MR, Kreger BT, Lien WH, Klezovitch O, Rudakova GM, Camargo FD, Lantz DM, Seykora JT, Vasioukhin V. alpha-catenin is a tumor suppressor that controls cell accumulation by regulating the localization and activity of the transcriptional coactivator Yap1. Sci Signal. 2011; 4:ra33.

25. RobinsonBS, Moberg KH. Cell-cell junctions: alphacatenin and E-cadherin help fence in Yap1. Curr Biol. 2011; 21:R890-892.

26. Cao JJ, Zhao XM, Wang DL, Chen KH, Sheng X, Li WB, Li MC, LiuWJ, He J. YAP is overexpressed in clear cell renal cell carcinoma and its knockdown reduces cell proliferation and induces cell cycle arrest and apoptosis. Oncol Rep. 2014; 32:1594-1600.

27. Yang Z, Zhang M, Xu K, Liu L, Hou WK, Cai YZ, XuP, Yao JF. Knockdown of YAP1 inhibits the proliferation of osteosarcoma cells in vitro and in vivo. Oncol Rep. 2014; 32:1265-1272.

28. Zhang J, SmolenGA, Haber DA. Negative regulation of YAP by LATS1 underscores evolutionary conservation of the Drosophila Hippo pathway. Cancer Res. 2008; 68:2789-2794.

29. Shao DD, Xue W, Krall EB, Bhutkar A, Piccioni F, Wang X, Schinzel AC, Sood S, Rosenbluh J, Kim JW, Zwang Y, Roberts TM, Root DE, et al. KRAS and YAP1 converge to regulate EMT and tumor survival. Cell. 2014; 158:171-184.

30. Ge L, Smail M, Meng W, Shyr Y, Ye F, Fan KH, Li X, ZhouHM, Bhowmick NA. Yes-associated protein expression in head and neck squamous cell carcinoma nodal metastasis. PloS one. 2011; 6:e27529.

31. Wang Y, Dong Q, Zhang Q, Li Z, WangE, Qiu X. Overexpression of yes-associated protein contributes to progression and poor prognosis of non-small-cell lung cancer. Cancer Sci. 2010; 101:1279-1285.

32. LiJ, Zhou BP. Activation of beta-catenin and Akt pathways by Twist are critical for the maintenance of EMT associated cancer stem cell-like characters. BMC cancer. 2011; 11:49.

33. Scanlon CS, Van Tubergen EA, InglehartRC, D'Silva NJ. Biomarkers of epithelial-mesenchymal transition in squamous cell carcinoma. J Dent Res. 2013; 92:114-121.

34. Konsavage WM, Jr,Yochum GS. Intersection of Hippo/YAP and Wnt/beta-catenin signaling pathways. Acta Biochim Biophys Sin. 2013; 45:71-79.

35. Tao J, Calvisi DF, Ranganathan S, Cigliano A, Zhou L, Singh S, Jiang L, Fan B, Terracciano L, Armeanu-Ebinger S, Ribback S, Dombrowski F, Evert M, et al. Activation of beta-catenin and Yap1 in human hepatoblastoma and induction of hepatocarcinogenesis in mice. Gastroenterology. 2014; 147:690-701.

36. BarryER, Camargo FD. The Hippo superhighway: signaling crossroads converging on the Hippo/Yap pathway in stem cells and development. Curr Opin Cell Biol. 2013; 25:247-253.

37. Rosenbluh J, Nijhawan D, Cox AG, Li X, Neal JT, Schafer EJ, Zack TI, Wang X, Tsherniak A, Schinzel AC, Shao DD, Schumacher SE, Weir BA, et al. beta-Catenin-driven cancers require a YAP1 transcriptional complex for survival and tumorigenesis. Cell. 2012; 151:1457-1473.

38. YuX, Li Z. Long non-coding RNA HOTAIR: A novel oncogene (Review). Mol Med Rep. 2015; 12:5611-5618.

39. Chen JS, Wang YF, Zhang XQ, Lv JM, Li Y, LiuXX, Xu TP. H19 serves as a diagnostic biomarker and up-regulation of H19 expression contributes to poor prognosis in patients with gastric cancer. Neoplasma. 2016; 63:223-230.

40. Li S, Yu Z, Chen SS, Li F, Lei CY, Chen XX, Bao JM, Luo Y, Lin GZ, PangSY, Tan WL. The YAP1 oncogene contributes to bladder cancer cell proliferation and migration by regulating the $\mathrm{H} 19$ long noncoding RNA. Urol Oncol. 2015; 33:427 e421-410.

41. Wang J, Wang H, Zhang Y, Zhen N, Zhang L, Qiao Y, Weng W, Liu X, Ma L, Xiao W, Yu W, Chu Q, PanQ, et al. 
Mutual inhibition between YAP and SRSF1 maintains long non-coding RNA, Malat1-induced tumourigenesis in liver cancer. Cell Signal. 2014; 26:1048-1059.

42. Guo C, WangX, Liang L. LATS2-mediated YAP1 phosphorylation is involved in HCC tumorigenesis. Int J Clin Exp Pathol. 2015; 8:1690-1697.

43. Moroishi T, Park HW, Qin B, Chen Q, Meng Z, Plouffe SW, Taniguchi K, Yu FX, Karin M, PanD, Guan KL. A YAP/ TAZ-induced feedback mechanism regulates Hippo pathway homeostasis. Genes Dev. 2015; 29:1271-1284.

44. Hiemer SE, Zhang L, Kartha VK, Packer TS, Almershed M, Noonan V, Kukuruzinska M, Bais MV, MontiS, Varelas X. A YAP/TAZ-Regulated Molecular Signature Is Associated with Oral Squamous Cell Carcinoma. Mol Cancer Res. 2015; 13:957-968.

45. Li M, Lu J, Zhang F, Li H, Zhang B, Wu X, Tan Z, Zhang L, Gao G, Mu J, Shu Y, Bao R, Ding Q, et al. Yes-associated protein 1 (YAP1) promotes human gallbladder tumor growth via activation of the AXL/MAPK pathway. Cancer Lett. 2014; 355:201-209.

46. Song S, Ajani JA, Honjo S, Maru DM, Chen Q, Scott AW, Heallen TR, Xiao L, Hofstetter WL, Weston B, Lee JH, Wadhwa R, Sudo K, et al. Hippo coactivator YAP1 upregulates SOX9 and endows esophageal cancer cells with stem-like properties. Cancer Res. 2014; 74:4170-4182.

47. Lorenzetto E, Brenca M, Boeri M, Verri C, Piccinin E, Gasparini P, Facchinetti F, Rossi S, Salvatore G,
Massimino M, Sozzi G, MaestroR, Modena P. YAP1 acts as oncogenic target of 11q22 amplification in multiple cancer subtypes. Oncotarget. 2014; 5:2608-2621. doi: 10.18632/ oncotarget.1844.

48. Xia Y, Chang T, Wang Y, Liu Y, Li W, LiM, Fan HY. YAP promotes ovarian cancer cell tumorigenesis and is indicative of a poor prognosis for ovarian cancer patients. PloS one. 2014; 9:e91770.

49. Talmadge JE, Singh RK, FidlerIJ, Raz A. Murine models to evaluate novel and conventional therapeutic strategies for cancer. Am J Pathol. 2007; 170:793-804.

50. O'Reilly MS, Holmgren L, Shing Y, Chen C, Rosenthal RA, Moses M, Lane WS, Cao Y, SageEH, Folkman J. Angiostatin: a novel angiogenesis inhibitor that mediates the suppression of metastases by a Lewis lung carcinoma. Cell. 1994; 79:315-328.

51. Wang L, Yin J, Wang X, Shao M, Duan F, Wu W, Peng P, Jin J, Tang Y, Ruan Y, SunY, Gu J. C-Type Lectin-Like Receptor 2 Suppresses AKT Signaling and Invasive Activities of Gastric Cancer Cells by Blocking Expression of Phosphoinositide 3-Kinase Subunits. Gastroenterology. 2016; 150:1183-1195 e1116.

52. Rashid OM, Nagahashi M, Ramachandran S, Dumur CI, Schaum JC, Yamada A, Aoyagi T, Milstien S, Spiegel S, Takabe K. Is tail vein injection a relevant breast cancer lung metastasis model? J Thorac Dis. 2013; 5:385-392. 